\title{
Field Trials of an Improved Cost-effective Device for Detecting Peridomestic Populations of Triatoma infestans (Hemiptera: Reduviidae) in Rural Argentina
}

\author{
GM Vazquez-Prokopec, LA Ceballos, OD Salomón*, RE Gürtler/+
}

\begin{abstract}
Laboratorio de Ecología General, Departmento de Ecología, Genética y Evolución, Universidad de Buenos Aires, Ciudad Universitaria, C1428EHA Buenos Aires, Argentina *Centro Nacional de Diagnóstico e Investigación en Endemo-epidemias, Administración Nacional de Laboratorios e Institutos de Salud "Dr. Carlos G. Malbrán”, Buenos Aires, Argentina
\end{abstract}

An improved device for detecting peridomestic Triatoma infestans consisting of one-liter recycled Tetra Brik milk boxes with a central structure was tested using a matched-pair study design in two rural areas in Argentina. In Olta (La Rioja), the boxes were installed beneath the thatched roofs and on the vertical wooden posts of each peridomestic structure. After a 5-month exposure, at least one of the recovered boxes detected $88 \%$ of the $24 \mathrm{~T}$. infestans-positive sites, and $86 \%$ of the 7 negative sites by timed manual collections at baseline. In Amamá (Santiago del Estero), the boxes were paired with the best performing prototype tested before (shelter unit). After 3 months, some evidence of infestation was detected in 89\% (boxes) and 79\% (shelters) of 18-19 sites positive by timed collections, whereas $19 \%$ and $16 \%$ of 32 negative sites were positive, respectively. Neither device differed significantly in the qualitative or quantitative collection of every sign of infestation. The installation site did not modify significantly the boxes' sampling efficiency in both study areas. As the total cost of each box was half as expensive as each shelter unit, the boxes are thus the most cost-effective and easy-to-use tool for detecting peridomestic T. infestans currently available.

Key words: Triatoma infestans - Chagas disease - surveillance - sampling - vector control - Argentina

Triatoma infestans (Klug), the main vector of Chagas disease in Argentina, Bolivia, Brazil, Paraguay, Peru and Uruguay, is the target of an elimination program called The Southern Cone Initiative (Schmunis et al. 1996). $T$. infestans infests domestic and peridomestic habitats almost exclusively (Zeledón \& Ravinovich 1981, Dias 1991), with sylvatic foci apparently existing only in Bolivia (Dujardin et al. 1987, Noireau et al. 2000). Although the transmission of Trypanosoma cruzi (Kinetoplastida: Tripanosomatidae) to humans mostly occurs in human habitations (the domestic environment)(Cecere et al. 1999, Cohen \& Gürtler 2001), peridomestic foci of T. infestans are very frequent and the most likely source of the bugs that reinfest human habitations after insecticide spraying (Dujardin et al. 1996, Cecere et al. 1997). Early detection of peridomestic sites reinfested by triatomine bugs is thus essential to assess the effects of control actions and to establish the need for additional operations.

The standard method to assess the occurrence and intensity of infestation by triatomine bugs in domestic and peridomestic sites has been timed manual collections using an irritant spray (the "flushing-out" method)

This study was supported by UNDP/World Bank/WHO (TDR) from the Special Program for Research and Training in Tropical Diseases, and the University of Buenos Aires.

${ }^{+}$Corresponding author. Fax: +54-11-4576.3384. E-mail: gurtler@bg.fcen.uba.ar

Received 12 April 2002

Accepted 12 July 2002
(Schofield 1978, Rabinovich et al. 1995). However, this method is costly, requires skilled staff, and lacks sensitivity and precision. An artificial shelter unit proved to be more sensitive in the detection of peridomestic foci of $T$. infestans than segments of bamboo cane lined with pleated paper or timed manual collections with an irritant (De Marco et al. 1999, Gürtler et al. 2001b). The shelter units accounted for several features of triatomine behavior (negative phototaxis, thigmotaxis, and preference for dry sites) and were resistant to weather conditions. However, they were expensive for large-scale triatomine surveillance programs, and because of the rigid plastic structure, the shelter units were not easily adaptable to many peridomestic sites differing in physical structure. Our general aim has been to improve the cost-effectiveness of the sensitive shelter units by using recycled, appropriate materials that could be easily handled by the affected rural populations. Such a tool is also indispensable to study the spatial and temporal dynamics of reinfestation at a community-wide scale.

In this study, we describe a simpler, equally sensitive and less expensive device than the shelter unit for detecting peridomestic triatomine foci. In two different rural areas in Argentina, we conducted matched-paired trials to assess the devices' effectiveness at peridomestic sites determined to be positive and negative for $T$. infestans by timed manual collections, and whether the installation site modified their sensitivity.

\section{MATERIALS AND METHODS}

Devices - The new devices were one-liter, recycled Tetra Brik ${ }^{\mathrm{TM}}$ (Tetra Pak Corp.) milk boxes measuring $16 \mathrm{x}$ $9.5 \times 6 \mathrm{~cm}$ (length, width, depth), hereafter called 'box'. Two versions of these boxes, which differed only in the 
location of the entrances, were designed for installation beneath the beams supporting the thatched roof, or on the vertical wooden posts of each structure (Fig. 1). Internally, the boxes contained a central column $(20 \mathrm{~cm}$ long and $4.5 \mathrm{~cm}$ in section) of accordion-folded corrugated paper (Fig. 1C), and a piece of corrugated paper lining the internal walls. All boxes had been washed with diluted detergent before field use, whereas other component materials had not been used or treated with any bug insecticide or attractant.

To install the boxes on the vertical posts, a single strand of wire was passed through each of two holes made on the two folded triangles located at the base and top of the box (Fig. 1A). The wire also held in place a $10 \times 12 \mathrm{~cm}$ piece of commercially available bovine leather (the languet), with the rough surface facing upwards and covering the $10 \times 1 \mathrm{~cm}$ entrance. The entrance was located at the bottom to intercept the bugs when they returned to the refuges after feeding or host-seeking activities (Fig. 1A). When the box was placed beneath and parallel to the horizontal beams supporting the thatched roof (Fig. 1B), the two entrances on the sides were also coated with a 10 $\mathrm{x} 12 \mathrm{~cm}$ piece of leather bounded flush to the beams with wire.

De Marco et al. (1999) described the shelter units. They consisted of a black plastic, wide-mouthed jar $(19 \mathrm{~cm}$ high and $10 \mathrm{~cm}$ diameter) with a screw cap at the top and two openings at the bottom, from which a languet of leather coating the floor extended to the outside. Internally, the shelter units contained a removable central column (Fig. 1C) and the walls were lined with corrugated paper.

Study sites - As part of a larger research project on the ecology and control of $T$. infestans, we first conducted a trial of the boxes in rural houses around Olta $\left(30.3^{\circ} \mathrm{S}\right.$, $66.2^{\circ} \mathrm{W}$ ), La Rioja, Argentina, from late April 1999 to November 1999. The area belongs to the Monte province of the phytogeographic Chaco region, and is semi-arid with a thorn forest (Cabrera \& Willink 1980). Olta is $471 \mathrm{~m}$ above sea level, and has a mean annual temperature of $19.3^{\circ} \mathrm{C}$, and the average annual rainfall is about $450 \mathrm{~mm}$. The houses had been sprayed with beta-cyfluthrin approximately 5-6 years before this trial. In view of the positive results obtained in Olta, we conducted a matched-pair field trial of boxes and shelter units in Amamá and nearby villages $\left(27.1^{\circ} \mathrm{S}, 63^{\circ} \mathrm{W}\right)$, Santiago del Estero, Argentina, between December 1999 and March 2000. The area belongs to the Chaco province of the phytogeographic Chaco region (Cabrera \& Willink 1980). Its environmental characteristics and history of infestation by $T$. infestans were described previously (Gürtler et al. 1999).

Study design - In Olta, two skilled bug collectors from the National Vector Control Program (NVCP) assessed the intensity of peridomestic infestation by $T$. infestans and other triatomine species from 20 April to 6 May 1999. The search was made using an irritant agent $(0.2 \%$ tetramethrin, Icona, Argentina) for $30 \mathrm{~min}$ per house, as described by Gürtler et al. (1995). All triatomine bugs were removed, identified to species and counted by stage, as described by Canale et al. (2000). Another person placed one or two pairs of numbered boxes per site in late June 1999. In total, 39 pairs of boxes were installed beneath the roofs and on the posts in 34 peridomestic sites at 26 houses. The peridomestic sites included 23 goat corrals and 2 chicken coops in which $T$. infestans had just been captured by timed manual collections, and 9 apparently uninfested sites (4 goat corrals, 1 pig pen, and 4 chicken coops).

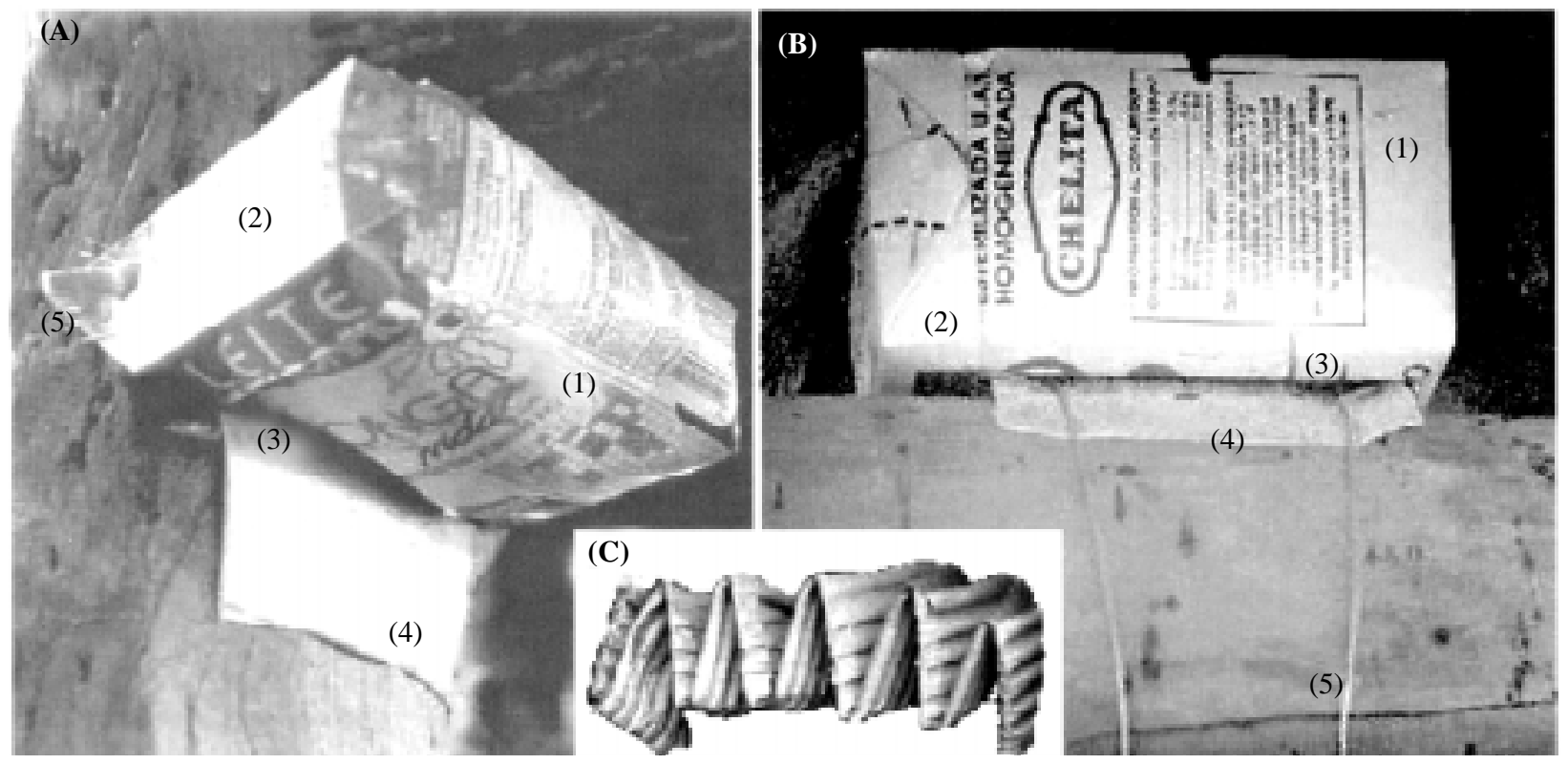

Fig. 1: Tetra Brik milk boxes used for detecting peridomestic Triatoma infestans and installed on the vertical wooden posts (A) or beneath the thatched roof (B) of each structure. The materials are: (1) Tetra Brik milk box cut on one end (2) to allow the introduction of the corrugated paper; (3) entrances; (4) leather languet; (5) wire that holds the box and the languet to the poles. (C) internal central column of accordion-folded corrugated paper. Black smears on the pole in B are triatomine dejecta. 
All boxes were inspected for evidence of infestation following standard procedures between 14 and 18 November 1999 (Gürtler et al. 2001b). Briefly, the boxes were handled inside a deep plastic tray to minimize the loss of eggs or other signs, and the number of triatomine bugs, exuviae, eggs and dejecta in the interior and exterior of each device were counted and recorded. Triatomine-like dejecta from the boxes were tested by the phenolphthalin (Kastle-Meyer) test (Gürtler et al. 2001a) to confirm the presence of heme (which is absent from other non-hematophagous arthropods' feces). A maximum of 10 dejecta per device was tested to verify that at least one was phenolphthalin-positive.

In Amamá, one or two matched pairs of shelter units and boxes were installed between 10 and 16 December 1999. A total of 79 pairs ( 37 beneath the roofs and 42 on the posts) were installed in 56 peridomestic sites at 40 houses. The 24 infested sites included 6 goat corrals, 4 pig pens, 9 storerooms, 1 oven, and 4 chicken coops in which $T$. infestans had been collected by timed manual collections in April 1999. The 32 negative sites included 9 goat or sheep corrals, 12 pig pens, 2 storerooms, 2 ovens, 6 chicken coops, and 1 pile of wood. Whenever possible, a pair of shelter units and boxes was installed beneath the roof and another pair on the posts, but in sites that did not allow a double installation, the pair that adapted best was chosen. Between 14 and 27 March 2000, two skilled bug collectors from NVCP searched for triatomines in all bedrooms and peridomestic areas of 114 houses using $0.2 \%$ tetramethrin (Icona, Argentina) for $30 \mathrm{~min}$ per house. All triatomine bugs were processed as in Olta. Simultaneously with the timed manual collections, all boxes and shelter units were inspected for evidence of triatomine infestation by another team. For timed manual collections, the term "infested" or "positive" meant finding at least one live or moribund T. infestans. For the devices, these terms meant that at least one sign of infestation (i.e., $T$. infestans bugs, eggs or exuvie, or triatomine fecal smears) was detected.
Data analysis - Given the matched-pairs study design, each pair of devices was taken as the sampling unit to test their relative effectiveness. Pairs with one missing device were excluded from analysis. In the absence of prior evidence, the sensitivity of devices was tested by the two-tailed binomial test (Zar 1996). The recovery rate of each device was tested by the McNemar test for paired data (Zar 1996). In Olta, the sampling efficiency of the boxes according to installation site was measured by the log-transformed ratios of the numbers of bugs or each sign of infestation recovered from each box placed on the post (x) to those in the matched box beneath the roof (y) of each peridomestic site $\left\{\log _{10}[(x+1) /(y+1)]\right\}$. The antilog of the mean $\log$ ratio is the geometric mean ratio. Using a similar procedure for data collected in Amamá, the relative sampling efficiency of the devices was measured by the log-transformed ratios of the numbers of bugs or each sign of infestation recovered from each box (x) to those in the matched shelter unit (y) at each installation site $\left\{\log _{10}[(\mathrm{x}+1) /(\mathrm{y}+1)]\right\}$. Variations in the density of triatomine dejecta among component materials were studied by Kruskal-Wallis test (Zar 1996).

\section{RESULTS}

In Olta, the total catch of $T$. infestans by timed manual collections from 25 infested peridomestic sites was 199 bugs (median, 3 bugs per site; first and third quartiles, Q1-Q3, 2-9.3) in late April 1999. In November 1999, the boxes that had been installed beneath the roofs were recovered significantly more frequently than those on the vertical posts ( $90 \%$ to $69 \%$, respectively; McNemar $\chi^{2}=$ 6.13; degrees of freedom, $d f=1, P=0.013$ ). All of the missing devices had been placed in goat or sheep corrals.

At least one of the recovered boxes detected some evidence of triatomine infestation in $88 \%$ of the positive sites, and in $86 \%$ of the sites that had been negative by timed collections in late April 1999 (Fig. 2). Both in positive and negative sites, the boxes on the posts were qualitatively more sensitive in detecting $T$. infestans bugs or
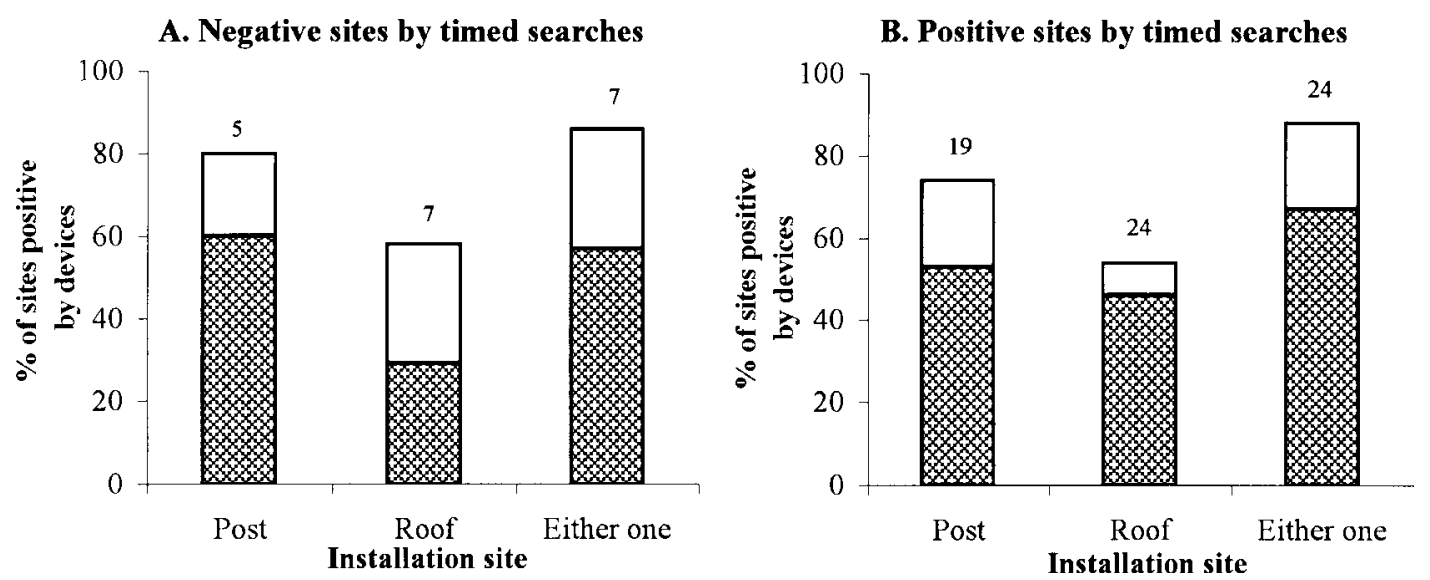

Fig. 2: infestations by Triatoma infestans detected in November 1999 using 1-2 Tetra Brik boxes according to installation site (on vertical posts and beneath the thatched roof) in peridomestic sites that had been negative (A) or positive (B) by timed manual collections in late April 1999, Olta and nearby villages, April 1999-November 1999. Empty bars are based on the finding of any sign of infestation, excluding T. garciabesi or T. guasayana; hatched bars are based on the finding of $T$. infestans bugs, exuviae or eggs. Numbers on top of each bar represent the total number of sites inspected for infestation by the recovered devices. 
any sign of infestation than those beneath the thatched roofs, although not significantly so (two-tailed binomial tests, $P>0.2$ ).

The frequency distribution of every sign in the positive devices was significantly different from a random distribution: T. infestans bugs $\left(\chi^{2}=58.5, d f=16, P<0.005\right)$, exuviae $\left(\chi^{2}=27.3, d f=9, P<0.005\right)$, eggs $\left(\chi^{2}=296.6, d f\right.$ $=19, P<0.005)$ or triatomine dejecta $\left(\chi^{2}=240.0, d f=30, P\right.$ $<0.005)$; the variance to mean ratios $(11,2,18$, and 10 , respectively) indicated strong aggregation. The boxes collected a similar total number of signs of infestation when placed beneath the roofs (443) or on the posts (393). When placed beneath the roofs rather than on the posts, the boxes' sampling efficiency did not differ significantly for T. infestans bugs (mean log ratio $\pm 95 \%$ confidence limits (C.L.), $0.03 \pm 0.29)$, exuviae (0.18 \pm 0.43$)$, eggs $(0.09 \pm 0.39)$ or triatomine dejecta $(0.17 \pm 0.25)$. The 67 bugs collected from the boxes in five negative sites were $76 \%$ I-II instar nymphs, $3 \%$ III-IV, $9 \% \mathrm{~V}$, and $12 \%$ adults, whereas in the positive sites the stage structure of the 78 bugs collected was $49 \%$ I-II, $13 \%$ III-IV, $17 \%$ V, and $21 \%$ adults. Both stage structures were significantly different $\left(\chi^{2}=32.6 ; d f\right.$ $=3 ; P<0.001)$. The density of triatomine dejecta per 100 $\mathrm{cm}^{2}$ in the languet (median, 1.6; Q1-Q3, 0.8-2.5) was significantly larger by at least one order of magnitude than in the accordion (median, 0.4; Q1-Q3, 0.2-0.8), wall lining (median, 0.4; Q1-Q3, 0.2-1.1) and the external surface (median, 0.6; Q1-Q3, 0.2-1.5)(Kruskal-Wallis, $\chi^{2}=10.1 ; d f=3$; $P=0.018)$.

In Amamá, the total timed manual catch of $T$. infestans from 24 infested peridomestic sites was 194 bugs in March
2000 (median per site, 5 bugs; Q1-Q3, 2-14). There were no significant differences in the recovery rate of the 79 pairs of boxes and shelter units when placed either beneath the thatched roof $\left(84 \%\right.$ and $92 \%$, respectively; McNemar $\chi^{2}=$ $0.57 ; d f=1 ; P=0.45)$, or on the vertical posts $(93 \%$ and $88 \%$, respectively; McNemar $\left.\chi^{2}=0.50 ; d f=1 ; P=0.48\right)$. After a three-month exposure, at least one of the recovered devices detected some evidence of triatomine infestation in $89 \%$ (boxes) and $79 \%$ (shelters) of positive sites, and in $19 \%$ (boxes) and $16 \%$ (shelters) of negative sites (Fig. 3)(two-tailed binomial tests, $P>0.5$ ).

A total of 1,361 and 1,265 signs of infestation (including 137 and 140 bugs) was recovered from the shelter units and boxes, respectively (Table I). The frequency distribution of every sign of infestation in the positive devices also was significantly different from a random distribution: $T$. infestans bugs $\left(\chi^{2}=530.9, d f=14, P<\right.$ $0.005)$, exuviae $\left(\chi^{2}=615.6, d f=28, P<0.005\right)$, eggs $\left(\chi^{2}=\right.$ 1676.9, $d f=26, P<0.005)$ and triatomine dejecta $\left(\chi^{2}=\right.$ $3689.35, d f=47, P<0.005)$; the variance to mean ratios $(14,18,24$ and 66 , respectively) again indicated strong aggregation. The boxes were as efficient as the shelters in the collection of every sign in either installation site (Fig. 4 ). When all signs of infestation were pooled, the relative sampling efficiency of the devices installed on the posts (mean $\log$ ratio $\pm 95 \%$ C.L., $-0.13 \pm 0.15$ ) or beneath the roofs $(0.02 \pm 0.31)$ was not significantly different. None of the correlation coefficients between the log ratios for each type of sign and bug catches by timed manual collection was statistically significant in either installation site (for all cases, $P>0.1)$.
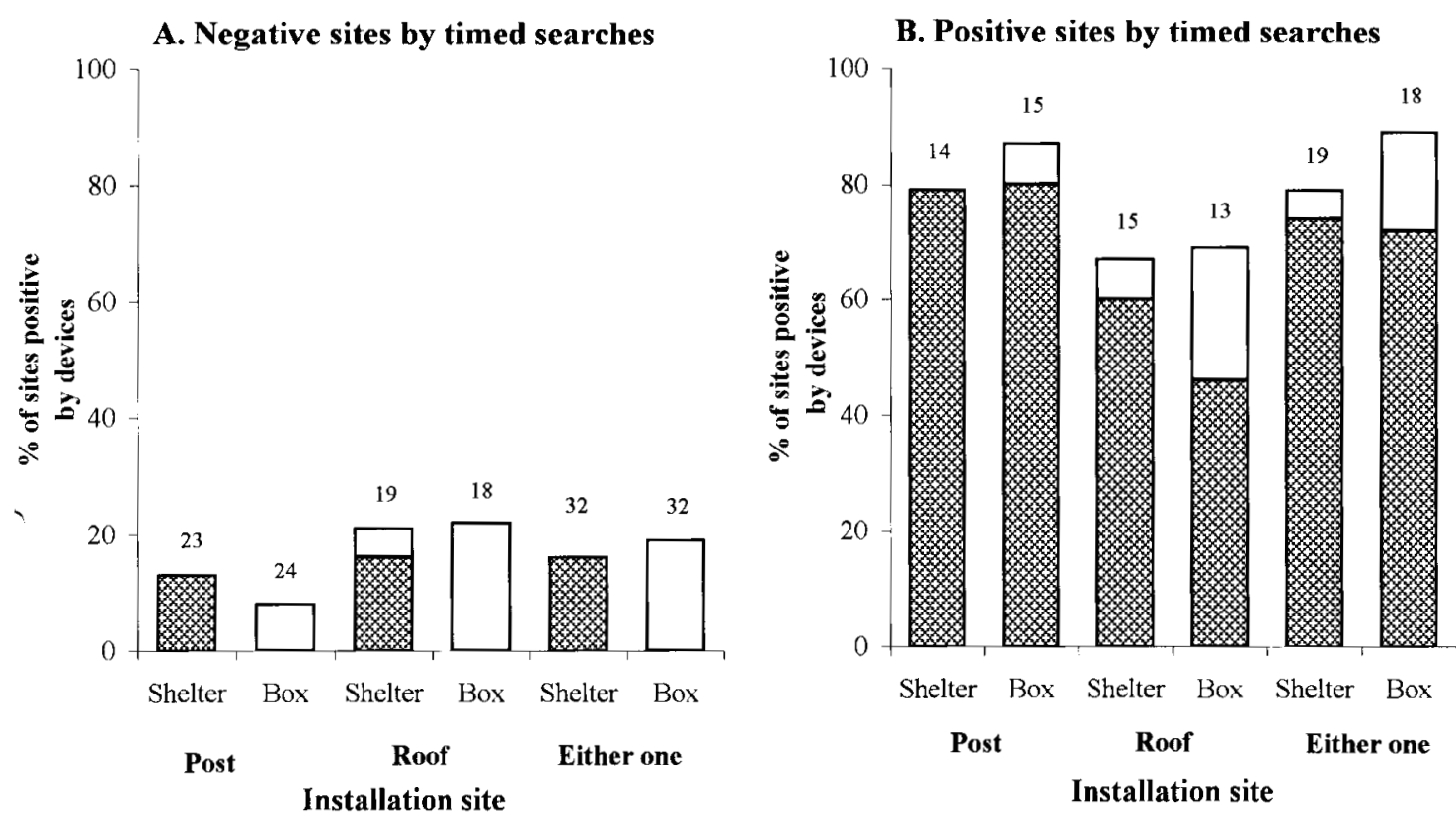

Fig. 3: infestations by Triatoma infestans detected in March 2000 using 1-2 matched pairs of shelter units and Tetra Brik boxes according to installation site (on vertical posts and beneath the thatched roof) in peridomestic sites that had been negative (A) or positive (B) by timed manual collections in March 2000, Amamá and nearby villages, December 1999-March 2000. Empty bars are based on the finding of any sign of infestation, excluding T. garciabesi or T. guasayana; hatched bars are based on the finding of T. infestans bugs, exuviae or eggs. Numbers on top of each bar represent the total number of sites inspected for infestation by the recovered devices. 
TABLE I

Number of Triatoma infestans bugs and signs of infestation recovered from the matched Tetra Brik boxes and shelter units installed beneath thatched roofs or on vertical posts, Amamá and nearby villages, December 1999-March 2000

\begin{tabular}{|c|c|c|c|c|c|c|}
\hline \multirow{2}{*}{$\begin{array}{l}\text { Installation } \\
\text { site } \\
\end{array}$} & \multicolumn{4}{|c|}{ No. of $T$. infestans } & \multirow{2}{*}{$\begin{array}{c}\text { No. of } \\
\text { triatomine } \\
\text { dejecta }\end{array}$} & \multirow[b]{2}{*}{ Total } \\
\hline & Device & Bugs & Exuviae & Eggs & & \\
\hline \multirow[t]{2}{*}{ Roof } & Shelter & 45 & 35 & 79 & 263 & 422 \\
\hline & Box & 38 & 17 & 262 & 148 & 465 \\
\hline \multirow[t]{2}{*}{ Post } & Shelter & 92 & 65 & 290 & 492 & 939 \\
\hline & Box & 102 & 98 & 155 & 445 & 800 \\
\hline \multirow[t]{2}{*}{ Total } & Shelter & 137 & 100 & 369 & 755 & 1,361 \\
\hline & Box & 140 & 115 & 417 & 593 & 1,265 \\
\hline
\end{tabular}
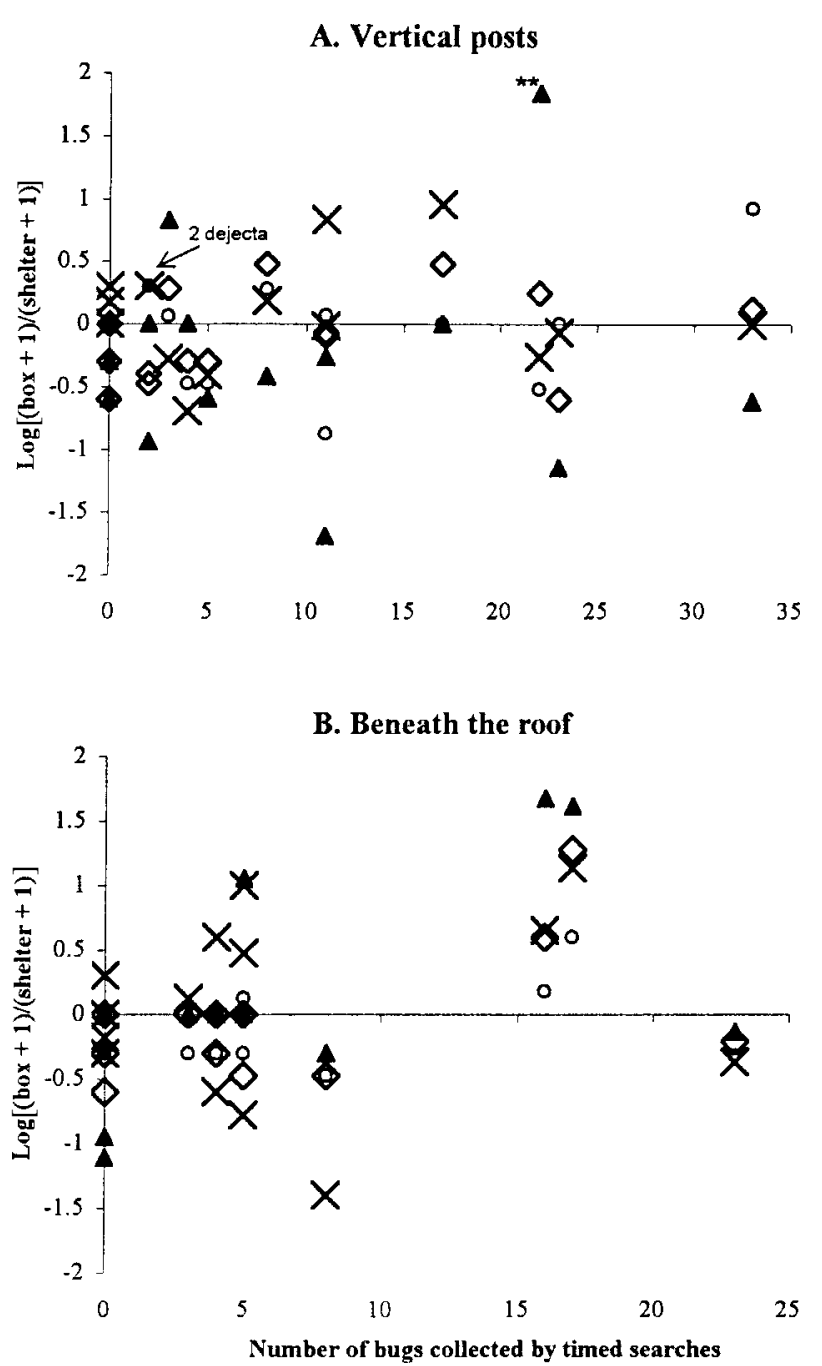

Fig. 4: log-ratios between the numbers of Triatoma infestans bugs $(\diamond)$, exuviae $(\mathrm{O})$, eggs $(\boldsymbol{\Delta})$ and triatomine dejecta $(\mathrm{X})$ collected by the Tetra Brik box and the shelter unit installed on vertical posts (A) or beneath the roofs (B), in the ordinate, and the total number of $T$. infestans bugs collected by timed manual searches in March 2000 , in the abcissa. Amamá and nearby villages, December 1999March 2000. Two overlapping points (X) in A are shown with an arrow.
The installation site modified the sampling efficiency of signs of infestation by shelter units but not by the boxes (Table I). Shelters installed on the posts collected significantly more $T$. infestans bugs (mean $\log$ ratio $\pm 95 \%$ C.L., $0.62 \pm 0.39)$, exuviae $(0.40 \pm 0.38)$, eggs $(0.57 \pm 0.42)$, triatomine dejecta $(0.61 \pm 0.52)$, or any sign of infestation $(0.67 \pm 0.56)$ than the paired shelters beneath the roofs. Despite clear differences at the aggregate level, paired boxes installed on the posts and beneath the roofs did not differ significantly in the collection of $T$. infestans bugs (mean $\log$ ratio $\pm 95 \%$ C.L., $0.27 \pm 0.98$ ), exuviae $(0.22$ $\pm 0.82)$, eggs $(-0.43 \pm 1.43)$, triatomine dejecta $(0.37 \pm 0.60)$, or any sign of infestation $(0.25 \pm 0.71)$. The density of triatomine dejecta per $100 \mathrm{~cm}^{2}$ in the languet (median, 5.8; Q1-Q3, 0.8-15) was significantly larger by at least one order of magnitude than in the accordion (median, 0.4; Q1Q3, 0-0.8), wall lining (median, 0.9; Q1-Q3, 0.2-4.7) and the external surface (median, 0.9; Q1-Q3, 0.4-0.2)(KruskalWallis, $\left.\chi^{2}=10.73 ; d f=3 ; P=0.013\right)$.

Shelters or boxes exposed for three months and timed manual collections with an irritant did not differ significantly in their capacity to detect some evidence of triatomine infestation (Table II). Both devices and timed searches detected some infestations that were missed by the alternative method. Results for shelter units and timed collections in Table II differ from those published before (Table III in Gürtler et al. 2001b) because the present data series includes more peridomestic sites exposed for a different and shorter time period (December to March). The stage structure differed significantly among methods $\left(\chi^{2}\right.$ $=57.7 ; d f=2 ; P<0.001)$. Timed manual collections were biased toward large stages; from 194 bugs collected, 55\% were adults, $17 \%$ V, $20 \%$ III-IV and $8 \%$ I-II. In contrast, the boxes collected 140 bugs, including $14 \%$ adults, $19 \% \mathrm{~V}$, $48 \%$ III-IV and $18 \%$ I-II nymphs, whereas the shelter units collected 137 bugs, including $32 \%$ adults, $18 \%$ V, 22\% IIIIV, and 29\% I-II. In negative sites, $T$. infestans bugs were found only in the shelters (6 I, $1 \mathrm{II}$ and $1 \mathrm{~V})$. The devices also detected $29 \mathrm{~T}$. garciabesi bugs and one T. guasayana bug. Spiders, crickets, small lizards (Gecko sp.), known to prey on triatomines, and cockroaches were also recovered from the devices.

A previous cost estimate for each shelter unit was US $\$ 1.74$ (Gürtler et al. 2001b), or US $\$ 0.50$ at June 12, 2002 prices. For the box, the current cost estimate is US $\$ 0.26$, and includes US\$0.14 for materials (leather, corrugated paper and wire) and US\$0.12 for 5 min of labor (cutting and assemblage, assuming US $\$ 1.43$ per labor hour). Additional expenses related to fieldwork, which for the shelter unit were US $\$ 0.40$ at 2002 prices, have been reduced to US $\$ 0.31$ for the box. These include search for a suitable site and deployment of devices, US\$0.12 or $5 \mathrm{~min}$; and inspection and reinstallation of devices, US\$0.19 or $8 \mathrm{~min}$.

\section{DISCUSSION}

Tetra Brik boxes were consistently as sensitive as the shelter units or timed manual collections with an irritant in detecting foci of $T$. infestans in a great variety of peridomestic ecotopes differing in construction materials, resident hosts and intensity of infestation both in $\mathrm{La}$ Rioja and Santiago del Estero Provinces. This is consis- 
TABLE II

Detection of peridomestic infestations by Triatoma infestans using 1-2 matched pairs of shelter units and Tetra Brik boxes exposed for three months, and timed manual collections with an irritant conducted in March 2000, Amamá and nearby villages. The numbers in the Table are for peridomestic sites

\begin{tabular}{lcccccc}
\hline Device & $\begin{array}{c}\text { Positive } \\
\text { by }{ }^{a} \text { only }\end{array}$ & $\begin{array}{c}\text { Positive only } \\
\text { by timed collections }\end{array}$ & $\begin{array}{c}\text { Positive by } \\
\text { both methods }\end{array}$ & $\begin{array}{c}\text { Negative by } \\
\text { both methods }\end{array}$ & $\begin{array}{c}\text { Missing } \\
\text { devices }\end{array}$ & $\begin{array}{c}\text { Two-tailed } \\
\text { binomial test }\end{array}$ \\
\hline Shelter & 5 & 4 & 27 & 15 & 5 & $P=1.00$ \\
Box & 6 & 2 & 26 & 16 & 6 & $P=0.29$ \\
\hline
\end{tabular}

a: positive means any sign of infestation: T. infestans bugs, exuviae or eggs, or triatomine fecal smears.

tent with previous results (Gürtler et al. 2001b) and supports the replacement of timed searches or shelter units by boxes for detecting and collecting peridomestic $T$. infestans.

Boxes and shelters revealed the presence of $T$. infestans bugs in sites where timed manual collections had been or were negative concurrently. This may be explained by 'false negative' results of timed collections or to recent bug colonization, because the bugs recovered from the devices installed in negative sites either were first-second instar nymphs and adults, or late instars and adults. Moreover, in Amamá both devices detected lowdensity infestations and other new foci missed by concurrent timed manual collections, in spite of all searches having been made by the same highly experienced bug collector. Clearly, rapid timed searches by skilled bug collectors may fail to detect many peridomestic foci of $T$. infestans that, in the absence of treatment, inevitably would increase in abundance and reinfest the treated areas.

Boxes and shelters apparently provided similarly suitable conditions that increased the bugs' residence time in the interior and the likelihood of leaving at least one sign of infestation, which is consistent with previous results (De Marco et al. 1999, Gürtler et al. 2001b). The aggregation behavior of several triatomine species is mediated by thigmotaxis and by volatiles present in their feces (Schofield \& Paterson 1977, Lorenzo Figueiras et al. 1994). Under laboratory conditions, $T$. infestans bugs apparently used feces as chemical marks left just outside their refuges (Lorenzo \& Lazzari 1996). Here we provide the first evidence that this pattern also occurs in the field, where the density of triatomine feces was significantly more abundant in the entrances (i.e., the leather languet) than inside the artificial refuges. Moreover, the large number of triatomine feces found in the devices could enhance both their attractiveness to $T$. infestans bugs and the chance of collecting more bugs, exuviae or eggs. Given the interspecific attraction of $T$. infestans bugs to feces of T. garciabesi and T. guasayana (Lorenzo Figueiras \& Lazzari 1998), which also infest peridomestic habitats in the study area, their feces may further increase the attractiveness of the artificial refuges for $T$. infestans.

Inappropriate installation of the devices may expose them to damage by the resident animals, as occurred in Olta, or to sunlight and rainfall, or may block the entrances to the bugs. Heavy rainfall did not negatively affect the materials used in either device or the subsequent finding of signs of infestation during the dry and wet seasons. It is highly likely that the Tetra Brik box and leather components may be used for many years, but the less expensive central cardboard structure may need replacement perhaps every six months. Tetra Brik boxes that are no longer usable can be recycled in several ways (available at http:/ /www.tetrapak.com).

The installation site of the shelter units significantly modified the likelihood of the bugs' leaving some sign of infestation, perhaps because the units' rigid plastic structure, size and shape did not fit adequately beneath the roof and may have restricted the access of bugs. Because the entrances and leather languets of shelters and boxes had the same size, other factors need to be invoked to explain variations in sampling efficiency related to installation site. In contrast, the installation site did not significantly modify the boxes' sampling efficiency of any sign of infestation in either study area, although the total number of signs collected on the vertical posts tended to be clearly larger than beneath the roof. We believe that this was caused by the boxes' effective interception of those bugs that returned back to the refuges in the thatch.

The box was as sensitive as the shelter in the collection of every sign of infestation in either installation site at a wide range of bug abundance. The frequency distribution of each type of sign of infestation within the boxes and shelters was aggregated, with most devices bearing few signs and a few devices showing many signs. This overdispersion may lead to confusion when overall ratios of signs, not ratios of individual pairs, are used to represent the devices' sampling efficiency. In contrast to light traps (Schweigmann et al. 1988) and yeast or mammalbaited traps (Lorenzo et al. 1998, Noireau et al. 1999), both shelters and boxes collected all nymphal stages and adults of $T$. infestans, including starved and recently fed $T$. infestans bugs (Leonardo A Ceballos et al. unpublished data).

The boxes have several advantages over the shelter unit regarding simplicity, ease for cutting, adaptability to the variable surface of wooden poles, and cost. The cost of the shelter units was reduced by nearly $50 \%$ because of the use of recycled milk boxes instead of plastic, and the reduction of labor time to assemble and set up the boxes in the field. Compared with the US\$17 annual cost of triatomine surveillance per rural house using timed manual searches with an irritant in Argentina in the early 1990s (Chuit et al. 1992)(US\$4.88 at 12 June 2002 prices), surveillance of peridomestic sites using boxes is clearly 
the most cost-effective tool currently available for largescale control programs, which are in need to cover some one million rural houses throughout Argentina. If found acceptable by householders, the boxes might be incorporated into community-based control programs, in which the periodic replacement of the central cardboard column could be linked to the search for evidence of peridomestic infestation by local villagers.

\section{ACKNOWLEDGEMENTS}

To Dr Sonia Blanco and her staff at the National Vector Control Program (Argentina) for providing active support throughout this study, and to Griseldo Roldán and Isaac Ochoa for expert assistance during fieldwork. Omar Sitatti kindly provided field accommodation. Kathe Rogerson kindly provided editorial assistance.

\section{REFERENCES}

Cabrera AL, Willink A 1980. Biogeografía de América Latina. In Monografía 13, Serie Biología, Organización de los Estados Americanos, Washington, DC, p. 69-75.

Canale DM, Cecere MC, Chuit R, Gürtler RE 2000. Peridomestic distribution of Triatoma garciabesi and Triatoma guasayana in north-west Argentina. Med Vet Entomol 14: 383-390.

Cecere MC, Castañera MB, Canale DM, Chuit R, Gürtler RE 1999. Trypanosoma cruzi infection in Triatoma infestans and other triatomines: long term effects of a control program in rural northwestern Argentina. Pan Am J Publ Health 5: 392-399.

Cecere MC, Gürtler RE, Canale D, Chuit R, Cohen JE 1997. The role of the peridomiciliary area in the elimination of Triatoma infestans from rural Argentine communities. Pan Am J Publ Health 1: 273-279.

Chuit R, Paulone I, Wisnivesky-Colli C, Bo R, Perez AC, SosaStani S, Segura EL 1992. Result of a first step toward community-based surveillance of transmission of Chagas' disease with appropriate technology in rural areas. Am J Trop Med Hyg 46: 444-450.

Cohen JE, Gürtler RE 2001. Modeling household transmission of American trypanosomiasis. Science 293: 694-698.

De Marco RJ, Gürtler RE, Salomón OD, Chuit R 1999. Smallscale field trial of a sensing device for detecting peridomestic populations of Triatoma infestans (Hemiptera: Reduviidae) in north-western Argentina. J Med Entomol 36: 884-887.

Dias JCP 1991. Chagas disease control in Brazil: Which strategy after the attack phase? Ann Soc Belge. Méd Trop 71 (Suppl. 1): 75-86.

Dujardin JP, Cardozo L, Schofield CJ 1996. Genetic analysis of Triatoma infestans following insecticidal control interventions in central Bolivia. Acta Trop 61: 263-266.

Dujardin JP, Tibayrenc M, Venegas E, Maldonado L, Desjeux $\mathrm{P}$, Ayala F 1987. Isozyme evidence of lack of speciation between wild and domestic Triatoma infestans (Heteroptera: Reduviidae) in Bolivia. J Med Entomol 24: 40-45.

Gürtler RE, Cecere MC, Canale D, Castañera MB, Chuit R, Cohen JE 1999. Monitoring house reinfestation by vectors of Chagas disease: a comparative trial of detection methods during a four-year follow-up. Acta Trop 72: 213-234.

Gürtler RE, Chuit R, Cecere MC, Castañera MB 1995. Detecting domestic vectors of Chagas disease: a comparative trial of six methods in north-west Argentina. Bull WHO 73: 487494.

Gürtler RE, Oneto ML, Cecere MC, Castañera MB, Canale D 2001a. A simple method to identify triatomine (Hemiptera: Reduviidae) feces in sensing devices used in vector surveillance programs. J Med Entomol 38: 147-152.

Gürtler RE, Vazquez-Prokopec GM, Ceballos LA, Lund Petersen C, Salomón OD 2001b. Comparison between two artificial shelter units and timed manual collections for detecting peridomestic Triatoma infestans (Hemiptera: Reduviidae) in rural northwestern Argentina. J Med Entomol 38: 429-436.

Lorenzo Figueiras AN, Keningstein A, Lazzari CR 1994. Aggregation in the haematophagous bug Triatoma infestans: Chemical signals and temporal pattern. J Ins Physiol 40: 311-316.

Lorenzo Figueiras AN, Lazzari CR 1998. Aggregation and interespecific responses in three species of triatominae. Mem Inst Oswaldo Cruz 93: 133-137.

Lorenzo MG, Lazzari CR 1996. The spatial pattern of defaecation in Triatoma infestans and the role of faeces as a chemical mark of the refuge. J Ins Physiol 42: 903-907.

Lorenzo MG, Reisenman CE, Lazzari CR 1998. Triatoma infestans can be captured under natural climatic conditions using yeast-baited traps. Acta Trop 70: 277-284.

Noireau F, Bastrenta B, Catalá S, Dujardin JP, Panzera F, Torres M, Perez R, GalvãoC, Jurberg J 2000. Sylvatic population of Triatoma infestans from the Bolivian Chaco: from field collection to characterization. Mem Inst Oswaldo Cruz, 95 (Suppl. I):119-122.

Noireau F, Flores R, Vargas F 1999. Trapping sylvatic triatominae (Reduviidae) in hollow trees. Trans $R$ Soc Trop Med Hyg 93: 13-14.

Rabinovich JE, Gürtler RE, Leal J, Piñero DF 1995. Density estimates of the domestic vector of Chagas disease, Rhodnius prolixus Ståhl (Hemiptera, Reduviidae), in rural houses in Venezuela. Bull WHO 73: 347-357.

Schmunis GA, Zicker F, Moncayo A 1996. Interruption of Chagas' disease transmission through vector elimination. Lancet 348: 1171.

Schofield CJ 1978. A comparison of sampling techniques for domestic populations of Triatominae. Trans $R$ Soc Trop Med Hyg 72: 449-455.

Schofield CJ, Patterson JW 1977. Assembly pheromone of Triatoma infestans and Rhodnius prolixus nymphs (Hemiptera: Reduviidae). J Med Entomol 13: 727-734.

Schweigmann N, Vallvé S, Muscio O, Guillini M, Alberti A, Wisnivesky-Colli C 1988. Dispersal flight by Triatoma infestans in an arid area of Argentina. Med Vet Entomol 2: 401-404.

Zar JH 1996. Biostatistical Analysis, 3rd ed., Prentice-Hall, Englewood Cliffs, New Jersey.

Zeledón R, Rabinovich JE 1981. Chagas disease: an ecological appraisal with special emphasis on its insect vectors. Ann Rev Entomol 26: 101-133. 
978 Device for Detecting Peridomestic T. infestans - GM Vazquez-Prokopec et al. 